\title{
Risk factors for disease severity among hospitalised patients with 2009 pandemic influenza A (H1N1) in Spain, April - December 2009
}

\author{
P Santa-Olalla Peralta (psantaolalla@msps.es) ${ }^{1,2}$, M Cortes-García $^{1,2}$, M Vicente-Herrero $^{1}$, C Castrillo-Villamandos $^{1}$, \\ P Arias-Bohigas ${ }^{1}$, I Pachon-del Amo ${ }^{1}$, M J Sierra-Moros ${ }^{1,2}$, on behalf of the Surveillance Group for New Influenza A(H1N1) Virus \\ Investigation and Control Team in Spain \\ 1. Ministerio de Sanidad y Política Social [Ministry of Health and Social Policy], Madrid, Spain \\ 2. These authors contributed equally to this report.
}

Citation style for this article:

Santa-Olalla Peralta P, Cortes-García M, Vicente-Herrero M, Castrillo-Villamandos C, Arias-Bohigas P, Pachon-del Amo I, Sierra-Moros MJ, on behalf of the Surveillance Group for New Influenza $A\left(\mathrm{H}_{1} \mathrm{~N}_{1}\right)$ Virus Investigation and Control Team in Spain. Risk factors for disease severity among hospitalised patients with 2009 pandemic influenza A (H1N1) in Spain, April - December 2009. Euro Surveill. 2010;15(38):pii=19667. Available online: http://www.eurosurveillance.org/ ViewArticle.aspx?Articleld $=19667$

We describe the clinical and epidemiological characteristics of patients hospitalised with confirmed 2009 pandemic influenza $A\left(\mathrm{H}_{1} \mathrm{~N}_{1}\right)$ in Spain from April to December 2009 and the risk factors associated with a worse outcome (admission to an intensive care unit or death) in adults. Case-based epidemiological information was collected as part of the national strategy for the surveillance of severe cases. Of 3,025 patients, 852 were admitted to an intensive care unit and overall, 200 died. The median patient age was 38 years (range: 0-94). A total of 662 (26\%) patients had no underlying risk conditions. Antiviral therapy was initiated within 48 hours after symptom onset in only $35.2 \%(n=711)$; the median length of time before treatment was four days. In a multivariate analysis, the start of antiviral therapy more than 48 hours after symptom onset (odds ratio (OR) 2.39; 95\% confidence interval (CI): 1.79 to 3.2 ), morbid obesity (OR: $2.01 ; 95 \% \mathrm{Cl} 1.38$ to 2.94), cardiovascular disease (OR: $1.79 ; 95 \% \mathrm{Cl}: 1.2$ to 2.67) and chronic obstructive pulmonary disease (OR: 1.51; $95 \% \mathrm{Cl}: 1.03$ to 2.2 ) were significantly associated with a worse outcome in adults.

\section{Introduction}

On 25 April 2009, the World Health Organization (WHO) declared the outbreak of the new influenza $A\left(\mathrm{H}_{1} \mathrm{~N}_{1}\right)$ viral infection, previously reported by the United States [1] and Mexico [2], a public health emergency of international concern under the International Health Regulations (2005) [3]. On 11 June 2009, WHO raised the pandemic alert level to phase 6 [4]. At the end of 2009, human infection with the pandemic virus had been reported in almost the whole world [5].

Following a previous alert issued by WHO on 24 April 2009 [6], Spain issued a national epidemiological alert and, on 27 April, reported the first laboratory-confirmed case of the 2009 pandemic influenza $A\left(\mathrm{H}_{1} \mathrm{~N}_{1}\right)$ in Europe [7]. On 26 June, in view of the evolving situation, the transition in Spain from containment to mitigation strategies, and under the new pandemic phase, a new national surveillance strategy was approved by the Public Health Commission of the Spanish Ministry of Health. One of the objectives of this surveillance was to detect severe influenza cases, identify their clinical, epidemiological and virological characteristics and assess their impact on the healthcare system. This ad hoc surveillance strategy was built on top of the existing Spanish National Surveillance Network, which covers all Spanish territory and has been in place since 1995. In addition to this surveillance strategy, the evolution of the pandemic was monitored through the influenza sentinel surveillance system and the investigation and follow-up of influenza outbreaks by regional health authorities.

The overwhelming majority of people infected worldwide with the 2009 pandemic virus have experienced uncomplicated influenza-like illness, with full recovery even without medical treatment [8]. However, it is still necessary to improve our knowledge of the epidemiological characteristics of small subsets of patients with very severe pulmonary complications [9-11]. Furthermore, while people with certain underlying medical conditions are known to be at increased risk for seasonal influenza complications, new risk factors, such as morbid obesity, have been suggested to be associated with pandemic influenza severity [12-14].

In this report, we describe the demographic characteristics, presence of risk factors, clinical findings and treatment of the first 3,025 patients who were hospitalised in Spain for severe pandemic influenza and notified to the Spanish Ministry of Health and Social Policy by the National Surveillance Network from 24 April 2009 to 15 December 2009. We also analyse the risk factors associated with a worse outcome (admission to an intensive care unit (ICU) or death) in adults. 


\section{Methods}

\section{Inclusion criteria}

Eligible patients included all adults and children admitted to any hospital in Spain with laboratory confirmation of 2009 pandemic influenza $\mathrm{A}\left(\mathrm{H}_{1} \mathrm{~N}_{1}\right)$ infection from 24 April to 15 December 2009. The national health system defines paediatric patients as those under the age of 15 years. The initial case definition for severe 2009 pandemic influenza $\mathrm{A}\left(\mathrm{H}_{1} \mathrm{~N}_{1}\right)$ disease included, among other criteria, severe respiratory infection or death by acute respiratory disease of unknown aetiology. Since June 2009, a specific case definition for severe cases has been adopted as part of the strategy for the surveillance of severe cases and has been applied to the whole country by the National Surveillance Network. Suspected severe cases were those:

- with clinical features compatible with influenza requiring hospitalisation for clinical severity;
- who developed these clinical features during hospitalisation for another reason; or

- with severe pneumonia admitted to ICUs in the absence of a known cause.

Diagnostic testing was clinically driven. All cases were confirmed by a specific reverse transcription-polymerase chain reaction (RT-PCR) for 2009 pandemic influenza $A\left(\mathrm{H}_{1} \mathrm{~N}_{1}\right)$ virus at either the national or regional reference laboratories. These laboratories were accredited by the national reference laboratory (the National Centre for Microbiology).

\section{Data collection}

This study was conducted as part of the routine activities in the institutions concerned, both at national and regional level. Data were collected by either

\section{TABLE 1}

Characteristics and underlying conditions of reported hospitalised patients with 2009 pandemic influenza A(H1N1) infection by outcome, Spain, 24 April - 15 December $2009(n=3,025)$

\begin{tabular}{|c|c|c|c|}
\hline \multirow[t]{2}{*}{ Patient details } & $\begin{array}{c}\text { Patients not admitted to an ICU } \\
\text { and who survived } \\
n=2,134\end{array}$ & $\begin{array}{c}\text { Patients admitted to an ICU } \\
\text { or who died } \\
n=891\end{array}$ & \multirow[t]{2}{*}{$p$ value $^{c}$} \\
\hline & Percentage (Number/Total) ${ }^{\mathrm{a}, \mathrm{b}}$ & Percentage (Number/Total) ${ }^{\mathrm{a}, \mathrm{b}}$ & \\
\hline \multicolumn{4}{|l|}{ General characteristics } \\
\hline Median age & 37 years (range: $0-94$ ) & 41 years (range: $0-92$ ) & $<0.001$ \\
\hline Female & $45.6(970 / 2,129)$ & $45.2(402 / 890)$ & 0.873 \\
\hline Current smoker ${ }^{d}$ & $32.1(313 / 974)$ & $34.5(183 / 531)$ & 0.012 \\
\hline \multicolumn{4}{|l|}{ Underlying conditions ${ }^{\mathrm{e}}$} \\
\hline Any chronic pulmonary disease & $35.5(687 / 1,933)$ & $34.8(281 / 807)$ & 0.726 \\
\hline Asthma & $22.7(362 / 1,594)$ & $14.5(101 / 698)$ & $<0.001$ \\
\hline COPD & $11.5(183 / 1,588)$ & $16.9(122 / 722)$ & $<0.001$ \\
\hline Morbid obesity ${ }^{\mathrm{d}, \mathrm{f}}$ & $11.1(120 / 1,080)$ & $19.3(119 / 616)$ & $<0.001$ \\
\hline Diabetes & $9.4(157 / 1,676)$ & $13.8(108 / 780)$ & $<0.001$ \\
\hline Other metabolic disease & $8.8(116 / 1,313)$ & $11.5(74 / 644)$ & 0.001 \\
\hline Pregnancy ${ }^{g}$ & $15.0(61 / 407)$ & $15.8(29 / 184)$ & 0.806 \\
\hline Cancer & $7.4(123 / 1,653)$ & $8.5(66 / 779)$ & 0.373 \\
\hline Immunodeficiency & $10.2(168 / 1,644)$ & $12.4(97 / 783)$ & 0.110 \\
\hline Cardiovascular disease $^{\mathrm{h}}$ & $9.6(159 / 1,657)$ & $16.1(125 / 778)$ & $<0.001$ \\
\hline Chronic hepatic disease & $6.1(81 / 1,322)$ & $9.0(59 / 657)$ & 0.025 \\
\hline Haemoglobinopathy or anaemia & $4.6(59 / 1,276)$ & $5.7(36 / 632)$ & 0.316 \\
\hline Cognitive dysfunction & $6.3(80 / 1,273)$ & $8.9(57 / 640)$ & 0.039 \\
\hline Seizures & $3.4(53 / 1,573)$ & $6.5(49 / 751)$ & 0.001 \\
\hline Chronic renal insufficiency & $4.1(52 / 1,283)$ & $7.3(47 / 644)$ & 0.003 \\
\hline Asplenia & $0.7(9 / 1,269)$ & $0.3(2 / 627)$ & 0.357 \\
\hline Neuromuscular disease & $4.1(52 / 1,260)$ & $4.9(31 / 627)$ & 0.407 \\
\hline Treatment with aspirin & $2.5(31 / 1,242)$ & $3.9(24 / 613)$ & 0.109 \\
\hline
\end{tabular}

COPD: chronic obstructive pulmonary disease; ICU: intensive care unit.

a Unless otherwise indicated.

b The number is the number of patients with a particular condition. The total is the total number of patients for whom the condition was recorded.

Comparison of patients not admitted to an ICU and who survived with patients admitted to an ICU or who died.

d Children under 15 years $(n=605)$ were excluded from the analysis of this variable.

e Conditions listed are not mutually exclusive: some patients had multiple underlying conditions.

Defined as body mass index of or greater than 40. Body mass index was calculated as weight in kilograms divided by the square of the height in metres.

$\mathrm{g}$ Data calculated using the number of female cases of reproductive age (15-44 years) as denominator. One pregnant case was not included because she was under 15 years.

h Excludes hypertension. 
infection-control physicians at hospitals or medical epidemiologists at local public health departments, as recommended by the national surveillance strategy for severe cases. Case-based information was gathered at the Coordinating Centre for Health Alerts and Emergencies at the Ministry of Health and Social Policy,

\section{FIGURE}

Number of co-morbidities of reported hospitalised patients with 2009 pandemic influenza A(H1N1) infection by outcome, Spain, 24 April - 15 December $2009(n=2,058)$

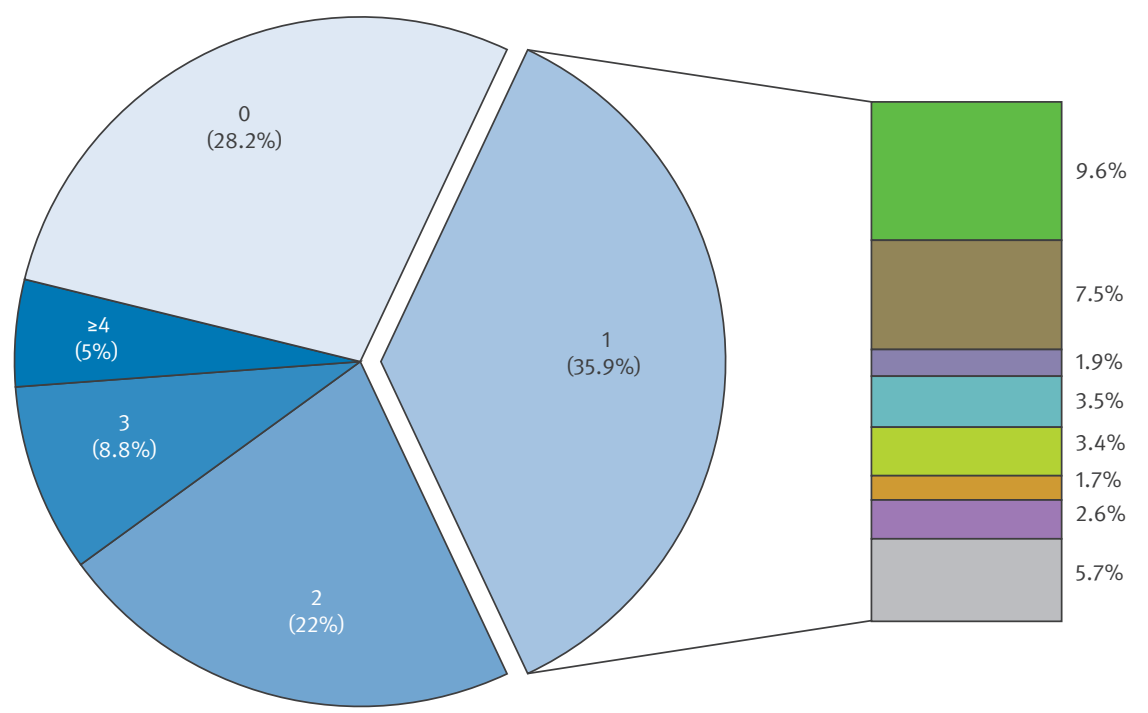

Asthma

$\square$ Chronic pulmonary disease ${ }^{a}$

$\square$ Cardiovascular disease ${ }^{\mathrm{b}}$

$\square$ Immunosuppressionc

$\square$ Metabolic disease ${ }^{\mathrm{d}}$

$\square$ Morbid obesity

$\square$ Pregnancy

$\square$ Other co-morbidities ${ }^{f}$

Number of co-morbidities (percentage of patients) in patients admitted to an ICU or who died $(n=786)$
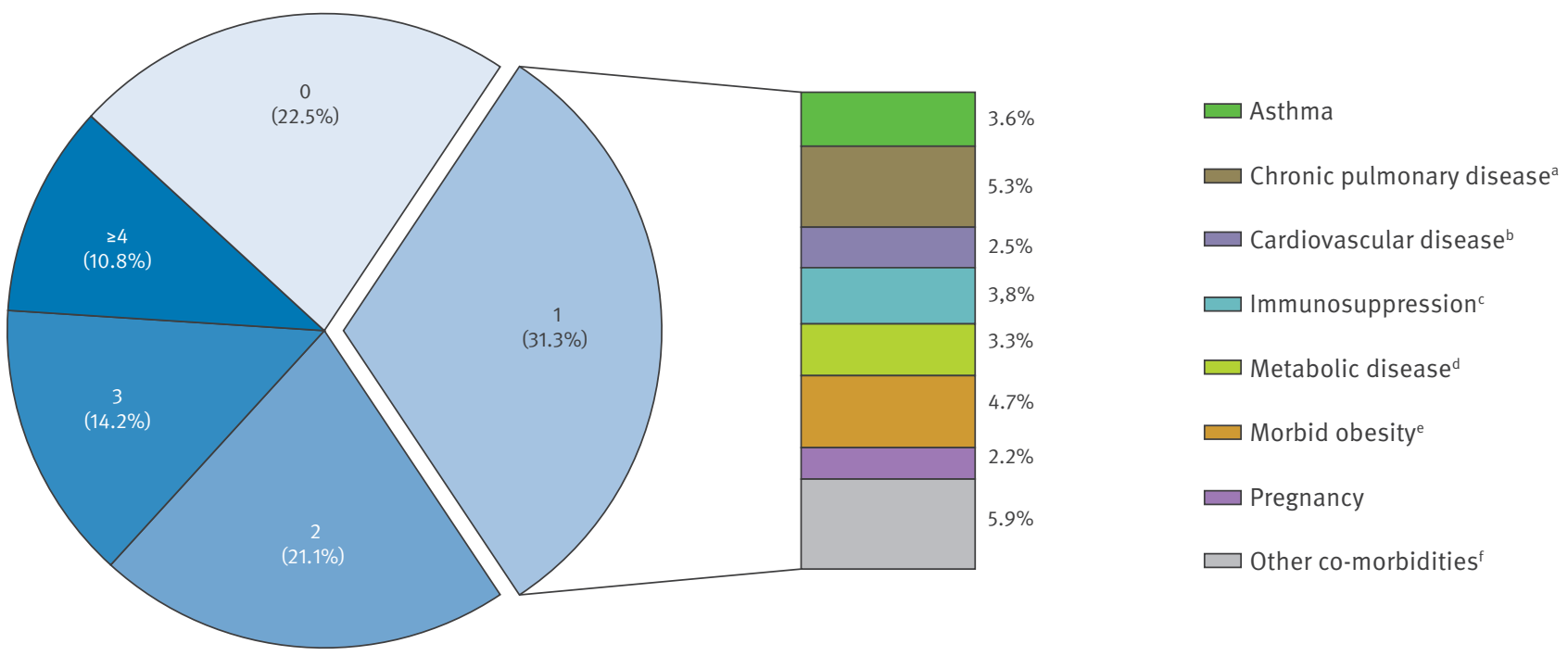

ICU: intensive care unit.

a Includes chronic obstructive pulmonary disease.

b Excludes hypertension.

c Includes cancer, asplenia and immunodeficiency.

d Includes diabetes.

e Defined as body mass index of or greater than 40. Body mass index was calculated as weight in kilograms divided by the square of the height in metres (adults only).

f Other co-morbidities include chronic hepatic disease, haemoglobinopathy and anaemia, cognitive dysfunction, seizures, chronic renal insufficiency, neuromuscular disease and treatment with aspirin. 
where it was reviewed and analysed. All cases were identified through the National Surveillance Network.

A standardised clinical form was used to collect demographic data (age and sex), underlying risk conditions for severe influenza, clinical characteristics, disease outcome and complications, treatment course and time course of illness.

Underlying risk conditions included all chronic diseases and conditions that constitute an indication for seasonal influenza vaccination in Spain, including pregnancy [15]. Current smoking status, cognitive dysfunction and body mass index (BMI) were also recorded. The last two were included based on data from other studies $[12,16,17]$. In this study, we report information on morbidly obese adults (with a $\mathrm{BMI} \geq 40$ ).
Disease outcome included three possible options: patients who were not admitted to an ICU and who survived; patients who were admitted to an ICU and patients who died. The last two categories were joined (admitted to an ICU or death) and were considered as the worst outcome for this analysis.

\section{Data analysis}

Information on each underlying risk condition was analysed and described independently. All percentages were calculated using the number of patients with available data as denominator. For pregnancy, proportions were calculated as a percentage of pregnant patients among female patients of reproductive age (15-44 years). An additional variable, the number of co-morbidities, was created, taking into account the number of underlying risk conditions associated with severe influenza reported for each patient. For this analysis, morbid obesity and cognitive dysfunction were

\section{TABLE 2}

Characteristics and underlying conditions of reported hospitalised patients with 2009 pandemic influenza A(H1N1) infection by age group, Spain, 24 April - 15 December $2009(n=3,022)^{\mathrm{a}}$

\begin{tabular}{|c|c|c|c|c|}
\hline \multirow{2}{*}{ Patient details } & $\begin{array}{l}\text { Patients aged }<15 \text { years } \\
\qquad n=605\end{array}$ & $\begin{array}{l}\text { Patients aged } 15-64 \text { years } \\
n=2,092\end{array}$ & $\begin{array}{l}\text { Patients aged }>64 \text { years } \\
n=325\end{array}$ & \multirow{2}{*}{ p value ${ }^{c}$} \\
\hline & $\begin{array}{c}\text { Percentage } \\
\text { (Number/Total) }^{\mathrm{b}}\end{array}$ & $\begin{array}{c}\text { Percentage } \\
\text { (Number/Total) }\end{array}$ & $\begin{array}{c}\text { Percentage } \\
(\text { Number/Total) }\end{array}$ & \\
\hline \multicolumn{5}{|l|}{ General characteristics } \\
\hline Female sex & $41.7(252 / 604)$ & $46.5(970 / 2,087)$ & $46.2(150 / 325)$ & 0.114 \\
\hline Current smoker $^{\mathrm{d}}$ & NA & $37.6(510 / 1,355)$ & $15 \cdot 3(32 / 209)$ & $<0.001$ \\
\hline No co-morbidities & $39.4(180 / 457)$ & $26.6(465 / 1,747)$ & $5.3(16 / 300)$ & $<0.001$ \\
\hline At least two co-morbidities & $23.6(108 / 457)$ & $38.2(668 / 1,747)$ & $67.7(203 / 300)$ & $<0.001$ \\
\hline \multicolumn{5}{|l|}{ Underlying conditions ${ }^{e}$} \\
\hline Any chronic pulmonary disease & $33.6(182 / 542)$ & $33.5(633 / 1,892)$ & $50.5(153 / 303)$ & $<0.001$ \\
\hline Asthma & $24.7(113 / 458)$ & $20.2(320 / 1,585)$ & $12.1(30 / 247)$ & $<0.001$ \\
\hline COPD & $0(0 / 450)$ & $13.0(208 / 1,595)$ & $36.9(97 / 263)$ & $<0.001$ \\
\hline Morbid obesity ${ }^{\mathrm{d}, \mathrm{f}}$ & NA & $14.1(207 / 1,471)$ & $14.2(32 / 225)$ & 0.918 \\
\hline Metabolic disease & $3.3(17 / 515)$ & $14.6(272 / 1,857)$ & $39.6(118 / 298)$ & $<0.001$ \\
\hline Diabetes & $0.8(4 / 472)$ & $9.9(169 / 1,707)$ & $33.5(92 / 275)$ & $<0.001$ \\
\hline Immunosuppression ${ }^{g}$ & $8.0(29 / 364)$ & $19.6(272 / 1,385)$ & $28.6(66 / 231)$ & $<0.001$ \\
\hline Cardiovascular disease $^{\text {h }}$ & $3.9(18 / 462)$ & $8.6(146 / 1,699)$ & $44.0(120 / 273)$ & $<0.001$ \\
\hline Neuromuscular disease & $7.7(28 / 364)$ & $3.7(48 / 1,315)$ & $3.4(7 / 207)$ & 0.003 \\
\hline Cognitive dysfunction & $9.8(35 / 358)$ & $6.3(84 / 1,341)$ & $8.5(18 / 213)$ & 0.054 \\
\hline Seizures & $9.0(40 / 446)$ & $3.5(57 / 1,627)$ & $2.0(5 / 250)$ & $<0.001$ \\
\hline Chronic hepatic disease & $1.9(7 / 376)$ & $8.9(122 / 1,377)$ & $4.9(11 / 225)$ & $<0.001$ \\
\hline Haemoglobinopathy or anaemia & $2.7(10 / 366)$ & $5.0(67 / 1,327)$ & $8.4(18 / 214)$ & 0.010 \\
\hline Chronic renal insufficiency & $0.8(3 / 366)$ & $4.5(61 / 1,342)$ & $16.1(35 / 218)$ & $<0.001$ \\
\hline Treatment with aspirin & $1.7(6 / 355)$ & $2.1(27 / 1,289)$ & $10.5(22 / 210)$ & $<0.001$ \\
\hline
\end{tabular}

COPD: chronic obstructive pulmonary disease; NA: not applicable.

a Data on age were missing for three patients.

b The number is the number of patients with a particular condition. The total is the total number of patients for whom the condition was recorded.

Comparison of patients by age group.

d Children under 15 years $(n=605)$ were excluded from the analysis of this variable.

e Conditions listed are not mutually exclusive: some patients had multiple underlying conditions.

Defined as body mass index of or greater than 40. Body mass index was calculated as weight in kilograms divided by the square of the height in metres.

g Includes cancer, asplenia and immunodeficiency.

h Excludes hypertension. 
considered as risk conditions whereas status as a current smoker was not. Co-morbidities were considered to be absent in patients for whom information on all underlying risk conditions was complete and reported as absent. If one or more underlying risk conditions were reported present, the number of co-morbidities would be the sum of these underlying conditions.

For time calculations, the day of admission was considered to be hospital day o. Length of stay was calculated as the time from day o to day of discharge or death; cases still in hospital when data were extracted for analysis (15 December 2009) were classified as missing for this variable.

We performed a bivariate analysis to compare the risk factors among patients who were not admitted to an ICU and who survived with those among patients who either were admitted to an ICU or who died. The Mantel-Haenszel chi-square test (or Fisher's exact test when appropriate) was used to compare discrete variables and the Wilcoxon rank-sum test to compare continuous variables. The statistical tests were two-sided. We used multivariate logistic regression models to further investigate associations with a worse outcome using those variables that were significant ( $p<0.05$ ) in the bivariate analysis of data from adults. The multivariate logistic regression analysis was only performed for adults because of the different type and distribution of underlying conditions in children.

\section{Ethical aspects}

Both the surveillance protocol and standardised clinical form were approved by the Public Health Board of the Spanish Ministry of Health and Social Policy. Our study was determined to be part of the public health response to the 2009 influenza pandemic and therefore no explicit ethical evaluation was necessary.

\section{Results}

From 24 April to 15 December 2009, a total of 3,025 severe cases of 2009 pandemic influenza $A\left(\mathrm{H}_{1} \mathrm{~N}_{1}\right)$ were notified to the Coordinating Centre for Health Alerts and Emergencies from the whole country. The first severe case reported was admitted to hospital on 12 June 2009 and the last on 5 December 2009. Of the 3,025 patients we studied, 852 required admission to an ICU. Overall 200 patients died, of whom two died before being admitted to hospital.

\section{Demographic characteristics}

The median age of the patients was 38 years (range: o-94 years). There was a significant difference ( $p<0.001$ ) between the median age of those who were not admitted to an ICU and who survived (37 years) and the median age of those who were either admitted to an ICU or who died (41 years). Overall, 605 (20\%) of the patients were children under 15 years and 325 (10.7\%) were aged 65 years or older. Patients aged under two years represented $5.5 \%$ of all severe cases and $27.3 \%$ of paediatric cases. Of the patients requiring admission to an ICU $(n=852), 15.4 \% \quad(n=131)$ were children and $11.2 \%(n=95)$ were over 64 years.

Of 3,019 patients, 1,372 (45.4\%) were female and 91 were pregnant $(15.2 \%$ of female patients of childbearing age). Information on gestational duration was available for 74 patients: 39 were in the third trimester

\section{TABLE 3}

Time course of illness and antiviral treatment of reported hospitalised patients with 2009 pandemic influenza A(H1N1) infection by disease severity, Spain, 24 April - 15 December $2009(n=3,025)$

\begin{tabular}{|c|c|c|c|c|}
\hline \multirow[t]{2}{*}{ Patient details } & \multicolumn{2}{|c|}{$\begin{array}{l}\text { Patients not admitted to an ICU } \\
\text { and who survived } \\
n=2,134\end{array}$} & \multicolumn{2}{|c|}{$\begin{array}{c}\text { Patients admitted to an ICU } \\
\text { or who died } \\
n=891\end{array}$} \\
\hline & $\begin{array}{l}\text { Number of } \\
\text { patients }^{a}\end{array}$ & $\begin{array}{l}\text { Median number of } \\
\text { days }(I Q R)^{b}\end{array}$ & $\begin{array}{l}\text { Number of } \\
\text { patients }^{a}\end{array}$ & $\begin{array}{l}\text { Median number of } \\
\text { days (IQR) }\end{array}$ \\
\hline \multicolumn{5}{|l|}{ Time course of illness } \\
\hline Interval between symptom onset and hospital admission ${ }^{c, d}$ & 1,997 & $3(1-5)$ & 796 & $3(2-6)$ \\
\hline Interval between hospitalisation and ICU admission & NA & NA & 811 & $0(0-1)$ \\
\hline Length of stay in hospital ${ }^{c, d}$ & 1,618 & $5(3-7)$ & 643 & $12(7-21)$ \\
\hline Length of stay in an ICU & NA & NA & 608 & $6(3-14)$ \\
\hline Duration of clinical illness ${ }^{d}$ & 1,573 & $8(6-11)$ & 636 & $17(11-25 \cdot 75)$ \\
\hline \multicolumn{5}{|l|}{ Antiviral treatment } \\
\hline Patients receiving any antiviral treatment & 1,961 & $90.1 \%$ & 818 & $92.2 \%$ \\
\hline Patients treated within 48 hours after symptom onset ${ }^{d}$ & 1,465 & $39.2 \%$ & 555 & $24 \cdot 5 \%$ \\
\hline Interval between symptom onset and start of treatment ${ }^{\mathrm{d}}$ & 1,465 & $3(2-5)$ & 555 & $5(3-7)$ \\
\hline Duration of antiviral treatment ${ }^{\mathrm{d}}$ & 1,107 & $5(4-5)$ & 322 & $5(4-9)$ \\
\hline
\end{tabular}

ICU: intensive care unit; IQR: interquartile range; NA: not applicable.

a Number of patients for whom this information was recorded.

b Unless otherwise indicated.

Excludes 54 cases with symptom onset after hospital admission.

d There was a significant difference in the values for this variable in the bivariate analysis (p<o.001) when comparing patients not admitted to an ICU and who survived with patients admitted to an ICU or who died. 
and 26 in the second. Of 90 pregnant patients of childbearing age, 29 (32.2\%) were admitted to an ICU. This percentage was similar in non-pregnant women of childbearing age (30.9\%).

\section{Underlying risk conditions}

The distribution of underlying risk conditions by outcome is described in Table 1. The most frequently reported co-morbidities were any chronic pulmonary disease (35.3\%) and morbid obesity (14.1\%). While asthma was more frequently reported in less severe cases (22.7\%), chronic obstructive pulmonary disease (COPD) was more frequent in those admitted to an ICU or who died (16.9\%).

Information on the number of co-morbidities was analysed in $82.9 \%(n=2,508)$ of the patients. Overall, $26.4 \%$ had no underlying conditions while $73.6 \%$ had at least one underlying risk condition $(60.8 \%$ of the children and $76.5 \%$ of adults); $39.1 \%$ had at least two such conditions. The number of co-morbidities reported in our cohort by outcome is summarised in the Figure. Details of the underlying conditions are presented for patients reporting only one co-morbidity. For patients with at least two underlying conditions, there was no frequent association of co-morbidities. In patients aged under 15 years, the likelihood of having a co-morbidity was significantly higher in those admitted to an ICU or who died compared with those not admitted to an ICU and who survived ( $73.2 \%$ versus $56.5 \%$ respectively; p<0.001).

Underlying disease was not equally distributed among age groups. More than a third of the children (39.4\%) (Table 2) and young adults $(33.6 \%$ of patients aged 15-44 years) had no co-morbidities. Among children with only one co-morbidity, $62.6 \%(n=109)$ had a chronic pulmonary disease, of which asthma accounted for $54.1 \%(n=59)$.

Among pregnant patients $(\mathrm{n}=91), 35$ had no co-morbidities and 16 had one co-morbidity, with asthma being the most frequently reported $(n=6)$.

Of the 1,696 adult patients with available information, $239(14.1 \%)$ were morbidly obese. Among the 173 morbidly obese patients with other underlying risk conditions, the most frequent were asthma or COPD $(n=80)$, diabetes $(n=64)$ and cardiovascular disease $(n=40)$. Of the 120 morbidly obese patients not admitted to an ICU and who survived, $\mathbf{2 4 . 2 \%}$ did not have other established risk factors for severe influenza. This percentage was higher (31.1\%) in the 119 of patients who were either admitted to an ICU or who died. Of the 44 morbidly obese patients who died, 12 (27.3\%) had no other underlying condition.

\section{Course of illness and antiviral treatment}

The time course of illness and antiviral treatment are described in Table 3. The time from the onset of illness to hospital admission was slightly higher in patients who were either admitted to an ICU or who died (median: three days; interquartile range (IQR): 2-6) when compared with patients who were not admitted to an ICU and who survived (median: three days; IQR: 1-5) (p<0.001).

Overall, 2,521 (90.7\%) of the 2,779 patients with available information received treatment with antiviral drugs. Adults $(2,090$ of 2,234$)$ were significantly more likely to be treated than children ( 431 of 544) $(93.6 \%$ versus $79.2 \%$; p 20.001$)$. Of 2,020 patients, 711 (35.2 \%) received treatment within 48 hours of symptom onset, including 507 (39.4\%) of 1,288 patients with underlying risk conditions for severe influenza. Overall, the median time from symptom onset to treatment with antiviral drugs was 4 days (IQR: 2-6). The time between symptom onset and the start of antiviral therapy was significantly longer in patients admitted to an ICU or who died (median: five days), compared with the same interval in those who were not admitted to an ICU and who survived (median: three days) (pro.001) (Table 3).

\section{Outcomes}

Of 2,739 patients with available information, 2,252 $(82.2 \%)$ had radiological findings consistent with primary viral pneumonia and 1,585 (73.4\%) had hypoxemia. A secondary bacterial infection was reported in $292(30.5 \%)$ of the 957 patients with available information. Among patients admitted to an ICU or who died, the most frequent complications reported were acute respiratory distress syndrome $(n=316,51.1 \%)$, sepsis $(n=209,35.2 \%)$, shock $(n=170,29.4 \%)$, acute renal failure $(n=120,20.1 \%)$ or multi-organ failure $(n=95,19 \%)$.

Of the 702 critically ill patients with available information, $438(62.4 \%)$ required mechanical ventilation for a median of five days (range: $1-35$ ) and 37 (6.9\%) required dialysis. The median length of ICU stay was six days (IQR: 3-14).

At the time of analysis, 200 patients had died; all but two had been hospitalised (they died before they could be hospitalised) and 161 (80.5\%) had been admitted to an ICU, with a median length of stay of eight days (IQR: 3-14). The median age of the patients who died was 46 years (range: three months - 92 years): 36 (18\%) were over 64 years and $21(10.5 \%)$ were under 15 years.

While $13.9 \%(n=27)$ of patients who died had no risk factors, $60.8 \%$ (118 of 194 ) had two or more underlying conditions. In patients who died, the most frequent co-morbidities were pulmonary disease (in 72 of 180 patients; COPD in 34 of 168 ) and morbid obesity (44 of 162). The median time from the onset of illness to death was 13 days (IQR: 7-21). Of the patients who died, 28 of 131 with available information (21.4\%) received antiviral therapy within 48 hours after the onset of symptoms.

\section{Comparison of cases by outcome}

We conducted a multivariate analysis on data from adult patients that included the patient's age and sex, underlying conditions (asthma, COPD, diabetes, morbid 
obesity, chronic renal insufficiency and cardiovascular disease) and start of antiviral therapy within 48 hours after symptom onset. The variables that were significantly associated with a worse outcome (admission to an ICU or death) were the start of antiviral therapy more than 48 hours after the onset of illness (OR: 2.39; $95 \%$ confidence interval $(\mathrm{Cl}): 1.79$ to 3.2 ; p<0.001), morbid obesity (OR: $2.01 ; 95 \% \mathrm{Cl}: 1.38$ to $2.94 ; p=0.001$ ), cardiovascular disease (OR: $1.79 ; 95 \% \mathrm{Cl}: 1.2$ to 2.67 ; $\mathrm{p}=0.005$ ) and COPD (OR: 1.51; $95 \% \mathrm{Cl}: 1.03$ to 2.2; $p=0.002)$.

\section{Discussion}

We report on one of the largest series to date of hospitalised patients infected with the 2009 pandemic influenza $A\left(\mathrm{H}_{1} \mathrm{~N}_{1}\right)$ virus during the first seven months of the pandemic. It covers the spectrum of severe disease experienced in 3,025 hospitalised patients in Spain, including 852 patients admitted to an ICU during the study period. Overall 200 patients died.

The surveillance of pandemic influenza cases began in Spain in April 2009 following WHO's alert [6], but it was not until June 2009 that the first severe cases were detected, probably reflecting the beginning of community transmission in Spain.

In contrast to seasonal influenza, and as previously described for this pandemic $[13,18-20]$, most of our hospitalised patients were young and middle-aged adults. However, if we take into account data from the Spanish influenza sentinel system on influenza rates in the community, the likelihood of having severe disease and dying from it appears to be higher in adults aged over 64 years. In our study, $11.2 \%$ of patients admitted to an ICU and $18 \%$ of those who died were aged over 64 years, although cases of influenza in the community in this age group represented only $2.5 \%$ of all estimated cases in Spain during the study period, based on data from the Spanish influenza sentinel system (personal communication, Amparo Larrauri-Cámara, 12 February 2010) and [21]. This is consistent with reports elsewhere $[14,22,23]$ and is probably explained by the fact that in our hospitalised cases the likelihood of an underlying co-morbidity increased with age: $60 \%$ of the patients under 15 years were reported to have a comorbidity, compared with $95 \%$ in those aged over 64 years.

As in seasonal influenza, most of our cases were people with underlying risk conditions: $71.8 \%$ of the patients not admitted to an ICU and who survived and $77.5 \%$ of those admitted to ICU or who died. The most common co-morbidities were COPD, asthma, morbid obesity and cardiovascular disease. These findings are in line with published reports from other countries $[13,14,19,24,25]$. The high prevalence of morbid obesity in our adult patients is striking ( $11 \%$ in those not admitted to an ICU and who survived and $19.3 \%$ in those admitted to an ICU or who died), when compared with the estimated $0.5 \%$ prevalence in the adult population in Spain [26]. The prevalence of all co-morbidities increased with disease severity, with the exception of asthma, which was more prevalent in patients not admitted to an ICU and who survived.

Another noteworthy finding in our study is the presence of neuromuscular disease $(7.7 \%)$, seizures $(9.0 \%)$ and cognitive dysfunction (9.8\%) in the paediatric patients, as has been previously described for children with severe pandemic influenza in the United States $[13,17]$. In Spain, morbid obesity and cognitive dysfunction had not been previously considered as conditions that should prompt seasonal influenza vaccination. As a result of our findings, the Vaccine's Board, coordinated by the Spanish Ministry of Health, has considered inclusion of people with each condition in the target groups for influenza vaccination.

Pregnancy has been previously reported as a possible risk factor for complications from the pandemic influenza $[27,28]$. The prevalence of pregnancy in female patients in our study $(15.2 \%)$ is higher than the $5.2 \%$ prevalence in Spanish females of reproductive age (extrapolated from the number of births in 2009 in Spain) [29]. However, the need for intensive care was similar in hospitalised pregnant women (32\%) and hospitalised non-pregnant women of childbearing age (31\%).

Patients who died were significantly older and had a higher prevalence of co-morbidities (86\%) than those who survived, suggesting that the presence of chronic illness may increase the likelihood of death. However, $13.9 \%$ of those who died were previously healthy people. Disease progression was rapid in patients who died, with a median time from symptom onset to death of 13 days.

In a multivariate analysis, we found that a delay in the start of antiviral therapy, morbid obesity, cardiovascular disease and COPD were independent risk factors for a worse outcome in adults. Cardiovascular disease and COPD had already been established as risk factors for seasonal influenza [30]. A possible link between obesity, especially morbid obesity, and disease severity in pandemic influenza patients has been pointed out by others [12-14]. However, this is one of the few studies [19] where obesity, specifically morbid obesity, has been found to be an independent risk factor for influenza severity (OR: $2.01 ; 95 \% \mathrm{Cl} 1: 38$ to 2.94 ). Of note, $31.1 \%$ of the morbidly obese patients who were admitted to an ICU or who died did not have any other established risk factors for severe influenza.

The median interval from the onset of illness to hospital admission was three days, with complications appearing early in the illness course. Primary viral pneumonia and severe hypoxemia requiring mechanical ventilation were the most common complications in our hospitalised cases. Critically ill patients experienced a rapid worsening that required intensive care within 24 
hours of hospital admission. Acute respiratory distress syndrome, sepsis and shock were the most frequent complications, each occurring in $30-50 \%$ of critically ill patients. These findings are consistent with reports from other countries [13,24,31].

Protocols that were current during the study period recommended antiviral treatment of individuals in atrisk groups and in all hospitalised cases. In our study, a high proportion ( $90.7 \%$ ) of patients received antiviral treatment. However, only around a third received it within 48 hours of symptom onset, regardless of their status as a risk group. This may be due to the fact that patients generally do not seek medical care immediately (median of three days from symptom onset to hospital admission). Data from this pandemic suggest that the use of antiviral drugs can reduce disease severity and mortality from the pandemic influenza, especially when such therapy is started early [13,32]. Our results support these findings, as patients who were admitted to an ICU or who died were less likely to have received such therapy within 48 hours after symptom onset (OR: 2.39; $95 \% \mathrm{Cl}: 1.79-3.2)$. Antiviral treatment should be started as soon as possible in hospitalised patients with suspected infection with the pandemic virus, especially in patients at increased risk for complications, including those who are morbidly obese.

Our data are subject to a number of limitations. As the data were gathered during an evolving public health alert, some considerations need to be borne in mind. First, the data were collected for surveillance purposes and provide mainly epidemiological information on cases hospitalised for severe pandemic influenza. Although they also provide some clinical details, they are not exhaustive. Second, inherent to surveillance in epidemic outbreaks, some data are incomplete. This may have affected the analysis of the presence of underlying risk conditions as we have been conservative when considering co-morbidities as absent. It is therefore possible that the actual percentage of cases with no underlying risk conditions for severe influenza may be more than the reported $26 \%$. Third, at the time of data extraction, case-based reporting of severe pandemic influenza to the central level had not been exhaustive in all regions, due either to delays in reporting or to differences in individual data collection. On the basis of individualised data from regions where reporting was complete and on aggregated data of severe hospitalised cases, we estimate that those analysed in this report represent more than $90 \%$ of the patients who died, $60 \%$ of those admitted to an ICU, and $35 \%$ of those not admitted to an ICU in Spain. The difference in these proportions may bias our results towards the null hypothesis, as non-reported hospitalised cases not admitted to an ICU may be less severe than those reported. However, when we analyse only data from regions with complete reporting, the results are consistent with those from the analysis of all reported cases. Finally, although this analysis does not cover the whole period of the pandemic, at the time of data extraction, the epidemic in Spain had reached its peak and was declining towards baseline levels, with an incidence rate of 78 cases per 100,000 population (week 49) [21]. Therefore, we do not believe that the characteristics of future severe cases will be different from those described in this report.

Data on pandemic influenza vaccination were not recorded in our study. Despite the absence of these data, we do not think this introduces bias in our results. In Spain, pandemic influenza vaccination started on 16 November 2009 and the reported coverage for the pandemic vaccine among target groups in Spain at the end of the study period was $13.8 \%$ (unpublished data). Only $415(13.7 \%)$ cases in our study had symptom onset after 15 November 2009.

In conclusion, our study confirms the role of cardiovascular disease and COPD as risk factors for severe influenza and highlights the importance of an early start of antiviral therapy, especially for patients with underlying risk conditions. Furthermore, it demonstrates that morbid obesity is an independent risk factor for influenza severity. Healthcare planners and providers should be aware of the potential for severe illness and death in morbidly obese influenza patients. These findings should be taken into account when planning, including vaccination strategies, for upcoming influenza seasons.

\section{Acknowledgements}

This report represents the contributions of numerous colleagues in local and regional public health services and laboratories who contributed to the surveillance and investigation of 2009 pandemic influenza $A\left(\mathrm{H}_{1} \mathrm{~N}_{1}\right)$ cases. We also thank colleagues at the National Centre for Epidemiology and National Centre for Microbiology for their support. In addition, we gratefully acknowledge the contributions of the physicians in the national health system throughout Spain who have provided information and support without which this report could not have been prepared.

The members of the Surveillance Group for New Influenza $\mathrm{A}\left(\mathrm{H}_{1} \mathrm{~N}_{1}\right)$ Virus Investigation and Control Team are public health professionals responsible for the surveillance of influenza in Spain at local, regional and central level.

\section{References}

1. Centers for Disease Control and Prevention (CDC). Update: swine influenza $A\left(\mathrm{H}_{1} \mathrm{~N}_{1}\right)$ infections--California and Texas, April 2009. MMWR Morb Mortal Wkly Rep. 2009;58(16):4357. Available from: http://www.cdc.gov/mmwr/preview/ $\mathrm{mmwrhtml} / \mathrm{mm} 5816 \mathrm{a} . \mathrm{htm}$

2. Centers for Disease Control and Prevention (CDC). Outbreak of swine-origin influenza $A\left(\mathrm{H}_{1} \mathrm{~N}_{1}\right)$ virus infection - Mexico, MarchApril 2009. MMWR Morb Mortal Wkly Rep. 2009;58(17):46770. Available from: http://www.cdc.gov/mmwr/preview/ mmwrhtml/mm5817a5.htm

3. World Health Organization (WHO). Swine influenza. 25 April 2009. Available from: http://www.who.int/mediacentre/news/ statements/2009/h1n1_20090425/en/index.html

4. World Health Organization (WHO). World now at the start of 2009 influenza pandemic. 11 June 2009. Available from: http:// www.who.int/mediacentre/news/statements/2009/h1n1_ pandemic_phase6_20090611/en/index.html 
5. World Health Organization (WHO). Pandemic $\left(\mathrm{H}_{1} \mathrm{~N}_{1}\right) 2009$ update 78.11 Dec 2009. Available from: http://www.who.int/ csr/don/2009_12_11a/en/index.html

6. World Health Organization (WHO). Influenza-like illness in the United States and Mexico. 24 April 2009. Available from: http://www.who.int/csr/don/2009_04_24/en/index.html

7. Surveillance Group for New Influenza $A\left(\mathrm{H}_{1} \mathrm{~N}_{1}\right)$ Virus Investigation and Control in Spain. New influenza $A\left(\mathrm{H}_{1} \mathrm{~N}_{1}\right)$ virus infections in Spain, April-May 2009. Euro Surveill. 2009;14(19). pii=19209. Available from: http://www.eurosurveillance.org/ ViewArticle.aspx?Articleld $=19209$

8. World Health Organization (WHO). Clinical features of severe cases of pandemic influenza. 16 October 2009. Available from: http://www.who.int/csr/disease/swineflu/notes/h1n1_clinical_ features_20091016/en/index.html

9. Perez-Padilla R, de la Rosa-Zamboni D, Ponce de Leon S, Hernandez M, Quinones-Falconi F, Bautista E, et al. Pneumonia and respiratory failure from swine-origin influenza $A\left(\mathrm{H}_{1} \mathrm{~N}_{1}\right)$ in Mexico. N Engl J Med. 2009;361(7):680-9.

10. Novel Swine-Origin Influenza $A\left(\mathrm{H}_{1} \mathrm{~N}_{1}\right)$ Virus Investigation Team, Dawood FS, Jain S, Finelli L, Shaw MW, Lindstrom S, et al. Emergence of a novel swine-origin influenza $A\left(\mathrm{H}_{1} \mathrm{~N}_{1}\right)$ virus in humans. N Engl J Med. 2009;360(25):2605-15.

11. Gómez-Gómez A, Magaña-Aquino M, García-Sepúlveda CA, Ochoa-Pérez UR, Falcón-Escobedo R, Comas-García A et al. Severe pneumonia associated with pandemic $\left(\mathrm{H}_{1} \mathrm{~N}_{1}\right)$ 2009 outbreak, San Luis Potosí, Mexico. Emerg Infect Dis. 2010;16(1):27-34.

12. Centers for Disease Control and Prevention (CDC). Intensivecare patients with severe novel influenza $A\left(\mathrm{H}_{1} \mathrm{~N}_{1}\right)$ virus infection - Michigan, June 2009. MMWR Morb Mortal Wkly Rep. 2009;58(27):749-52. Available from: http://www.cdc.gov/ $\mathrm{mmwr} / \mathrm{preview} / \mathrm{mmwrhtml} / \mathrm{mm} 5827 \mathrm{a} 4 . \mathrm{htm}$

13. Jain S, Kamimoto L, Bramley AM, Schmitz AM, Benoit $\mathrm{SR}$, Louie J, et al. Hospitalised patients with $2009 \mathrm{H}_{1} \mathrm{~N}_{1}$ influenza in the United States, April-June 2009. N Engl J Med. 2009;361(20):1925-44.

14. Louie JK, Acosta M, Winter K, Jean C, Gavali S, Schechter R, et al. Factors associated with death or hospitalization due to pandemic 2009 influenza $A\left(\mathrm{H}_{1} \mathrm{~N}_{1}\right)$ infection in California. JAMA. 2009;302(17):1896-902.

15. Ministerio de Sanidad y Política Social. [Immunizations in adults]. Madrid; Ministerio de Sanidad y Política Social; 2004. [Accessed 19 Feb 2010]. Spanish. Available from: http://www. msc.es/ciudadanos/proteccionSalud/vacunaciones/docs/ recoVacunasAdultos.pdf

16. Centers for Disease Control and Prevention (CDC). Hospitalised patients with novel influenza $A\left(\mathrm{H}_{1} \mathrm{~N}_{1}\right)$ virus infection California, April-May 2009. MMWR Morb Mortal Wkly Rep. 2009;58(19):536-41. Available from: http://www.cdc.gov/ mmwr/preview/mmwrhtml/mm5819a6.htm

17. Centers for Disease Control and Prevention (CDC). Surveillance for pediatric deaths associated with 2009 pandemic influenza A ( $\left.\mathrm{H}_{1} \mathrm{~N}_{1}\right)$ virus infection - United States, April-August 2009. MMWR Morb Mortal Wkly Rep. 2009;58(34):941-7. Available from: http://www.cdc.gov/mmwr/preview/mmwrhtml/ mm5834a1.htm

18. Health Protection Agency (HPA). Pandemic (H1N1) 2009 in England: an overview of initial epidemiological findings and implications for the second wave. v4. 2 Dec 2009. Available from: http://www.hpa.org.uk/web/HPAwebFile/ HPAweb_C/1258560552857

19. Fuhrman C, Bonmarin I, Paty AC, Duport N, Chiron E, Lucas E, et al. Severe hospitalised 2009 pandemic influenza $\mathrm{A}\left(\mathrm{H}_{1} \mathrm{~N} 1\right)$ cases in France, 1 July-15 November 2009. Euro Surveill. 2010;15(2). pii: 19463. Available from: http://www. eurosurveillance.org/ViewArticle.aspx?Articleld=19463

20. van 't Klooster TM, Wielders CC, Donker T, Isken L, Meijer A, van den Wijngaard CC, et al. Surveillance of hospitalisations for 2009 pandemic influenza $A\left(\mathrm{H}_{1} \mathrm{~N}_{1}\right)$ in the Netherlands, 5 June - 31 December 2009. Euro Surveill 2010;15(2). pii: 19461. Available from: http://www.eurosurveillance.org/ViewArticle. aspx?Articleld $=19461$

21. Instituto de Salud Carlos III. [Weekly bulletin of the influenza surveillance system in Spain (SVGE). Week 492009 (from 6 to 12 December 2009)]. Madrid; Instituto de Salud Carlos III: 2009. Spanish. Available from: http://www.isciii.es/htdocs/ centros/epidemiologia/pdf/grn4909.pdf

22. Donaldson LJ, Rutter PD, Ellis BM, Greaves FE, Mytton OT, Pebody RG, et al. Mortality from pandemic A/H1N1 2009 influenza in England: public health surveillance study. BMJ. 2009;339:b5213.
23. New South Wales public health network. Progression and impact of the first winter wave of the 2009 pandemic $\mathrm{H}_{1} \mathrm{~N}_{1}$ influenza in New South Wales, Australia Euro Surveill. 2009;14(42). pii: 19365. Available from: http://www. eurosurveillance.org/ViewArticle.aspx?Articleld=19365

24. Domínguez-Cherit G, Lapinsky SE, Macias AE, Pinto R, Espinosa-Perez $L$, de la Torre A, et al. Critically Ill patients with 2009 influenza $A\left(\mathrm{H}_{1} \mathrm{~N}_{1}\right)$ in Mexico. JAMA 2009;302(17):1880-7.

25. Centers for Disease Control and Prevention (CDC). Deaths and hospitalizations related to 2009 pandemic influenza $A\left(\mathrm{H}_{1} \mathrm{~N}_{1}\right)$ - Greece, May 2009-February 2010. MMWR Morb Mortal Wkly Rep. 2010;59(22):682-6. Available from: http://www.cdc.gov/ $\mathrm{mmwr} / \mathrm{preview} / \mathrm{mmwrhtml} / \mathrm{mm} 5922 \mathrm{a2} . \mathrm{htm}$

26. Aranceta J, Pérez Rodrigo C, Serra Majem L, Ribas Barba L, Quiles Izquierdo J, Vioque J, et al. [Prevalence of obesity in Spain: results of the SEEDO 2000 study]. Med Clin (Barc). 2003;120(16):608-12. Spanish.

27. Jamieson DJ, Honein MA, Rasmussen SA, Williams JL, Swerdlow DL, Biggerstaff MS, et al. H1N1 2009 influenza virus infection during pregnancy in the USA. Lancet. 2009;374(9688):451-8.

28. Denholm JT, Gordon CL, Johnson PD, Hewagama SS, Stuart RL, Aboltins $\mathrm{C}$, et al. Hospitalised adult patients with pandemic $\left(\mathrm{H}_{1} \mathrm{~N}_{1}\right) 2009$ influenza in Melbourne, Australia. Med J Aust. 2010;192(2):84-6.

29. Instituto Nacional de Estadística. Population now-casts based on the 2001 census. [Accessed 19 Feb 2010]. Madrid: Instituto Nacional de Estadística; 2010. Available from: http://www.ine. es/jaxiBD/menu.do? $\mathrm{L}=1 \&$ divi $=\mathrm{EPOB} \& \mathrm{his}=0$ \&type $=\mathrm{db}$

30. Influenza vaccines. Wkly Epidemiol Rec. 2005;80(33):279-87.

31. Kumar A, Zarychanski R, Pinto R, Cook DJ, Marshall J, Lacroix J, et al. Critically ill patients with 2009 influenza $A\left(\mathrm{H}_{1} \mathrm{~N}_{1}\right)$ infection in Canada. JAMA. 2009;302(17):1872-9.

32. Centers for Disease Control and Prevention (CDC). Updated interim recommendations for the use of antiviral medications in the treatment and prevention of influenza for the 2009-2010 season. 7 December 2009. Available from: http://www.cdc. gov/h1n1flu/recommendations.htm 